\title{
THE NOVEL METHOD TO SYNTHESIS OF CANTHARIDIN INTERMEDIATE
}

\author{
Chunbin TAN, Xiaoling LIU and Hongfei DU* \\ Chongqing Academy of Chinese Materia Mediea, No. 34, Nanshan Road, Nanan District of Chongqing, 400065, China
}

Received July 23, 2018

\begin{abstract}
Sulfur-containing dehydrocantharidin(SD) was yielded ( $76 \%$ to $96 \%$ ) by Diels-Alder reaction in an ionic-liquid system under ordinary pressure and temperature. We explored the influences of different ionic-liquid types, reaction temperatures, and reaction times in this reaction. We found that the optimal reaction temperature was about $35^{\circ} \mathrm{C}$, the reaction time was $20 \mathrm{~h}$, and the most suitable ionic liquid was 1-butyl-3-methylimidazolium tetrafluoroborate. Furthermore, in the recycling process of ionic liquid, we found that $\mathrm{CH}_{3} \mathrm{CN}$ was the most suitable extraction solvent. We explored four steps in the synthetic route to SD and achieved a good yield of $38 \%$ in total. We envisage that this process could be further developed at an industrial scale for the synthesis of Cantharidin and is destined to be an environmentally friendly way to solve the lack of cantharis as a natural resource.
\end{abstract}

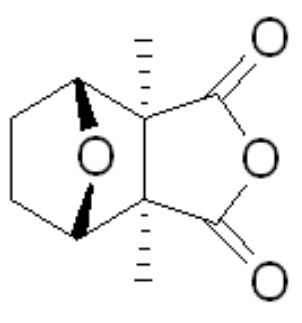

\section{INTRODUCTION}

Cantharidin, which can be extracted from cantharis ${ }^{1}$, is an antineoplastic drug that can have an effect on liver cancer, cervical cancer, skin cancer, bone marrow cancer, and leukemia. ${ }^{2-5}$ Cantharidin causes less damage to normal cells in cancer patients and elevates their white cell, without suppressing the immune systems. ${ }^{6,7}$ Cantharidin has been identified as one of the research hot spots for antitumor drugs. Because of the lack of natural resources for cantharis, the Cantharidin tablets or other pharmaceutical preparations cannot be realized at an industrial scale.

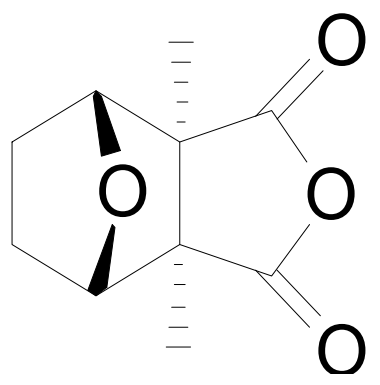

Fig. 1 - The structure of Cantharidin.
The three-dimensional structure of Cantharidin was given by Gadamer in 1914 (Fig. 1). ${ }^{8}$ Following this work, its national synthesis was committed to the pincers element of chemical synthesis, and some chemists achieved its total synthesis. In 1951, Stork synthesized Cantharidin for the first time using 11 steps. $^{9}$ In 1953, Schenk improved the synthetic route, reducing it to six steps. ${ }^{10}$ In 1976, Dauben Synt-hesized it and used just two key steps. ${ }^{11}$ Cantharidin cannot be obtained in high total yield after a long synthesis route, however, and some intermediates were difficult to synthesize under ordinary conditions. Although Dauben synthesized Sulfur-containing dehydrocanthari- din(SD) by Diels-Alder (D-A) reaction under 15000 atmospheric pressure, it is difficult to achieve this in industrial production.

The D-A reaction represents an important reaction in the synthesis of Cantharidin. Over the past decade, it has been a focus of research to ease the harsh conditions in the D-A reaction to prepare Cantharidin and to improve the yield of Cantharidin. In 1990, Grieco synthesized SD by

\footnotetext{
${ }^{*}$ Corresponding author: tcb204@163.com
} 
D-A reaction in lithium perchlorate $\left(\mathrm{LiClO}_{4}\right)$, improving the target yield, ${ }^{12}$ but this $\mathrm{D}-\mathrm{A}$ reaction requires strict water-free conditions. In 1999, Earle used ionic liquids in common D-A reactions. ${ }^{13}$ In 2003, Idiko found that zinc or aluminum salts could be used to change the ratio of endo/exo in a D-A reaction in ionic-liquid systems. ${ }^{14}$

In this paper, we show the newly touching to the SD synthesized by the D-A reaction in an ionic-liquid system under ordinary conditions (Fig. 2). In this process, SD can be obtained at a high yield from the D-A reaction under ordinary pressure and normal temperature. At the same time, the ionic liquids can be recycled to reduce costs in an environmentally friendly manner. High yield and good exo/endo selectivity, high ionic-liquid recycling efficiency, and mild reaction conditions are some of the advantages of this green process to synthesize SD. These advantages also offer good opportunities for the industrial production of Cantharidin.

\section{EXPERIMENTAL}

\section{Reagents and Chemicals Instrumentation}

Furan was dried using magnesium sulfate. Nuclear magnetic resonance (NMR) data were recorded on an
Agilent Technologies $600 \mathrm{MHz}$ DD2 (Santa Clara, CA). Electrospray ionization-mass spectrometry (ESI-MS) data were recorded on a Waters Acquity ${ }^{\circledR}$ SQD (Milford, MA).

2,5-dihydrothiophene-3,4-dicarboxylic acid anhydride followed the route in refs. ${ }^{11,15,16}$ The final and key step to prepare SD followed refs. ${ }^{13,14}$

\section{Synthesis of Methyl Thioglycolate ( I )}

A mixture of methanol $(0.4 \mathrm{~mol})$ and mercapto acetic acid $(1 \mathrm{~mol})$ was refluxed while stirred and concentrated $\mathrm{H}_{2} \mathrm{SO}_{4}$ $(0.8 \mathrm{~g})$ was added to the solution. Then the mixture was refluxed for $4 \mathrm{~h}$. After, the mixture was extracted three times with Cyclohexane $(80 \mathrm{~mL})$ and toluene $(40 \mathrm{~mL})$, then the extractive solution was dried using $\mathrm{CaCl}_{2}$, the solvent was evaporated in a vacuum to yield the colorless liquid (34g, $94 \%)$.

Synthesis of $\alpha, \beta$-dicarbomethoxymethyl ethyl sulfide (II)

I $(0.1 \mathrm{~mol})$ and pyridine $(0.2 \mathrm{~mL})$ was cooled in an ice bath while stirred $30 \mathrm{~min}$. Additionally, methyl acrylate $(1.1 \mathrm{~mol})$ was added to the solution and it was maintained at room temperature, after $5 \mathrm{~h}$ the mixture solution was washed with water and dried using $\mathrm{NaSO}_{4}$. The dried oil was distilled under vacuum to give a viscous oil of II, $17 \mathrm{~g}$.Yield: $88.8 \%$; b.p: $168 \sim 170^{\circ} \mathrm{C}$ under $6 \mathrm{KPa} ;{ }^{1} \mathrm{H}$ NMR $\left(\mathrm{CDCl}_{3}\right) \delta$ : $2.61(\mathrm{t}, 2 \mathrm{H}, \mathrm{J}=6 \mathrm{~Hz}), 2.86(\mathrm{t}, 2 \mathrm{H}, \mathrm{J}=9 \mathrm{~Hz}), 3.21$ (s, 2H), 3.65 $(\mathrm{s}, 3 \mathrm{H}), 3.69(\mathrm{~s}, 3 \mathrm{H}) ;{ }^{13} \mathrm{C}$ NMR $\left(\mathrm{CDCl}_{3}\right) \delta: 27.51,33.41$, $34.03,51.78,52.38,170.66,172.00 \mathrm{ppm}$; ESI-MS: $\mathrm{m} / \mathrm{z}$ $215.03\left(\mathrm{M}+\mathrm{Na}^{+}, 100 \%\right)$.

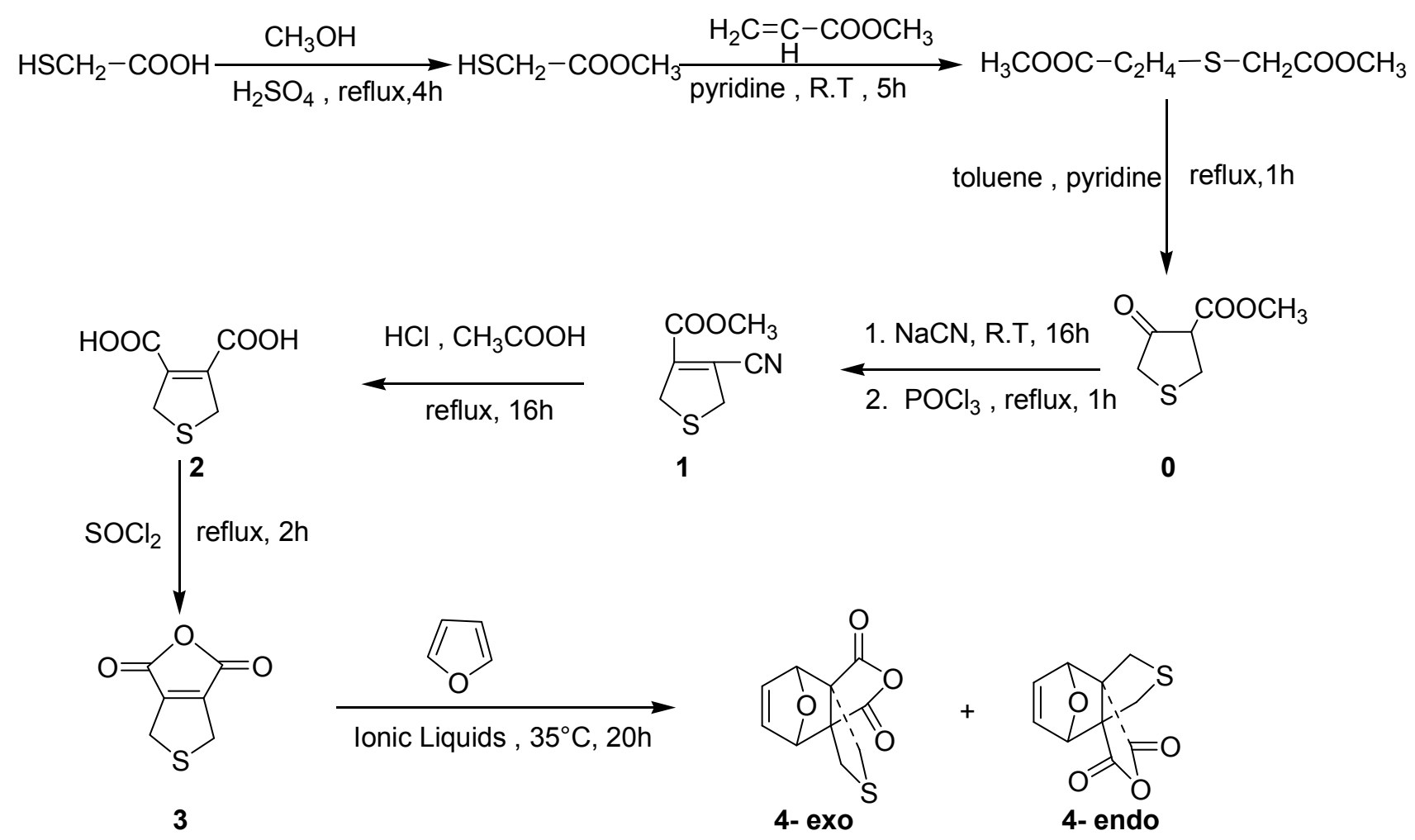

Fig. 2 - The synthetic route to SD under ambient pressure. 
Synthesis

of 3-keto-4-carbomethoxy-2,5-tetrahydrothiophene (0)

Pyridine $(0.2 \mathrm{~mol})$ and toluene $(500 \mathrm{~mL})$ was stirred under $80^{\circ} \mathrm{C}$ for $10 \mathrm{~min}$, then (II) $(0.2 \mathrm{~mol})$ was added to the solution and it was maintained at the temperature $80^{\circ} \mathrm{C}$ for $1 \mathrm{~h}$. In addition of (II) $(0.2 \mathrm{~mol})$ was added to the mixture in 20 min and the solution was refluxed for $1 \mathrm{~h}$. When cooled down to the room temperature, the samples adjusted to $\mathrm{pH} 7$ with $0.5 \mathrm{M}$ hydrochloric acid in the ice-sodium chloride cold bath, and the toluene layer were separated. Residual solution was extracted based on ether $(3 * 50 \mathrm{~mL})$, and combined with toluene layer. The mixture was evaporated to dryness in a vacuum, recrystallization from petroleum ether-anhydrous ethanol gave $38.4 \mathrm{~g}$ of yellowish-white crystals (compound 0),Yield:80\%; mp : 36 38 ${ }^{\circ} \mathrm{C} ;{ }^{1} \mathrm{H} \mathrm{NMR}\left(\mathrm{CDCl}_{3}\right) \delta: 3.75(\mathrm{t}$, $2 \mathrm{H}, \mathrm{J}=3 \mathrm{~Hz}), 3.78(\mathrm{~s}, 3 \mathrm{H}), 3.81$ (t, 2H, J=3 H z), 10.93 (s, $1 \mathrm{H}) ;{ }^{13} \mathrm{C} \mathrm{NMR}\left(\mathrm{CDCl}_{3}\right) \delta: 31.40,38.03,51.63,99.21$, 169.55, 172.43 ppm; ESI-MS: m/z183.01 (M+Na ${ }^{+}$, $100 \%)$.

Synthesis

of 3-Cyano-4-carbomethoxy-2,5-dihydrothiophene (1)

$\mathrm{NaHSO}_{3}(113 \mathrm{~g})$ and $600 \mathrm{~mL}$ purified water were added to an $\mathrm{NaCN}$ aqueous solution (176 g, 23\%), and the solution was cooled in an ice bath while stirred. Additionally, 80 g 3-keto-4-carbomethoxy-2,5-tetrahydrothiophene was added to $25 \mathrm{~mL}$ of methanol and the solution was maintained at room temperature. After $16 \mathrm{~h}$, the mixture was extracted three times with $200 \mathrm{~mL}$ $\mathrm{CH}_{2} \mathrm{Cl}_{2}$ and the solvent was evaporated in a vacuum to yield the yellow crude cyanohydrin $(90 \mathrm{~g}, 96 \%)$.

Without further purification, $123 \mathrm{~g}$ phosphoryl chloride $\left(\mathrm{POCl}_{3}\right)$ was added to $40 \mathrm{~g}$ of 3-hydroxyl-4-carbomethoxy-2,5- tetrahydrothiophene, $50 \mathrm{~mL}$ benzene, and $70 \mathrm{~g}$ pyridine and the solution was cooled in an ice bath while stirred. The temperature was maintained between $50^{\circ} \mathrm{C}$ and $60^{\circ} \mathrm{C}$, and $2 \mathrm{~h}$ later, the mixture was evaporated to dryness in a vacuum. Recrystallization from heptane-methylene chloride gave $28.8 \mathrm{~g}(80 \%)$ of white crystals (compound 1). ${ }^{1} \mathrm{H} \mathrm{NMR}\left(\mathrm{CDCl}_{3}, \mathrm{TMS}\right) \delta: 3.86$ $(\mathrm{s}, 3 \mathrm{H}), 4.04 \sim 4.0(\mathrm{~m}, 2 \mathrm{H}), 4.08 \sim 4.10(\mathrm{~m}, 2 \mathrm{H}) ;{ }^{13} \mathrm{C} \mathrm{NMR}$ $\left(\mathrm{CDCl}_{3}\right) \delta: 38.3,40.3,52.9,113.3,120.5,146.6,161.4$ ppm; ESI-MS: m/z $170.02\left[\mathrm{M}+\mathrm{H}^{+}, 100 \%\right]$.

Synthesis

of 2,5-dihydrothiophene- 3,4-dicarboxylic Acid (2)

A mixture of $36 \mathrm{~g}$ compound $1,110 \mathrm{~mL}$ acetic acid, and $180 \mathrm{~mL}$ concentrated hydrochloric acid was refluxed for $16 \mathrm{~h}$ and then the mixture was evaporated to dryness in a vacuum. The residue was extracted with hot acetone, filtered, and evaporated to dryness to obtain $35.2 \mathrm{~g} \mathrm{(95 \% )}$ of white crystals (compound 2). ${ }^{1} \mathrm{H}$ NMR (DMSO) $\delta$ : $3.96(\mathrm{~s}, 4 \mathrm{H}) ;{ }^{13} \mathrm{C}$ NMR (DMSO) $\delta: 40.0,138.5$, 165.7ppm; ESI-MS: m/z $175.0\left[\mathrm{M}+\mathrm{H}^{+}, 100 \%\right]$.

\section{Synthesis}

of 2,5-dihydrothiophene-3,4-dicarboxylic Acid Anhydride (3)

A mixture of $16 \mathrm{~g}$ compound 2 and $64 \mathrm{~mL} \mathrm{SOCl}_{2}$ was refluxed for $2 \mathrm{~h}$ and the mixture was evaporated to dryness in a vacuum. Recrystallization first from the $\mathrm{CH}_{2} \mathrm{Cl}_{2}$ and then from the $\mathrm{CH}_{3} \mathrm{CN}$ produced $6 \mathrm{~g} \mathrm{(33 \% )} \mathrm{of}$ white needle crystals (compound 3). ${ }^{1} \mathrm{H}$ NMR $\left(\mathrm{CDCl}_{3}\right.$, TMS) $\delta: 4.0(\mathrm{~s}, 4 \mathrm{H}) ;{ }^{13} \mathrm{C} \mathrm{NMR}\left(\mathrm{CDCl}_{3}\right) \delta: 31.5,153.9$, 158.5; ESI-MS: m/z178.98 (M+Na $\left.{ }^{+}, 100 \%\right)$.

\section{Synthesis of Sulfur-containing dehydrocantharidin (4,SD)}

A mixture of $0.5 \mathrm{~g}$ compound 3 and $0.26 \mathrm{~mL}$ 1-butyl-3-methylimidazolium tetrafluoro -borate was reacted with $5 \mathrm{~mL}$ of freshly dried furan at $35^{\circ} \mathrm{C}$. After 20 $\mathrm{h}$, the mixture was extracted with $\mathrm{CH}_{3} \mathrm{CN}(3 * 1 \mathrm{~mL})$ to obtain $0.6 \mathrm{~g}$ of a white solid, and 1-butyl-3-methylimidazoliumtetrafluoroborate remained in the $\mathrm{CH}_{3} \mathrm{CN}$. We performed additional studies by changing the types of ionic liquids from 1-butyl-3-methylimid- azoliumtetrafluoroborate to other ionic liquids in this reaction. ${ }^{1} \mathrm{H} \mathrm{NMR}\left(\mathrm{CDCl}_{3}, \mathrm{TMS}\right) \delta$ : $3.1(\mathrm{~d}, 2 \mathrm{H}), 3.5(\mathrm{~d}, 2 \mathrm{H}), 5.0(\mathrm{~s}, 2 \mathrm{H}), 6.7$ (s, 2H); ESI-MS:

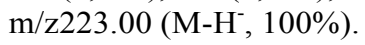

\section{RESULTS AND DISCUSSION}

\section{Advantages and disadvantages of the two different methods to prepare 3-cyano-4-carbomethoxy-2,5-dihydrothiophene}

For the synthesis of 3-cyano-4-car- bomethoxy-2,5-dihydrothiophene (compound 1), the use of liquid hydrogen cyanide ( $\mathrm{HCN}$ ) for $15 \mathrm{~h}$ at a low temperature around $10 \sim 20^{\circ} \mathrm{C}$ was reported. ${ }^{9,13}$ In the past, however, processing to remove excess $\mathrm{HCN}$ by bubbling nitrogen $\left(\mathrm{N}_{2}\right)$ proved to be difficult, and the HCN safe limit point could not be reached even after several hours of $\mathrm{N}_{2}$ bubbling. When the liquid HCN was replaced by sodium cyanide $(\mathrm{NaCN})$, the reaction time could be shortened to $10 \mathrm{~h}$ at room temperature. When $\mathrm{NaCN}$ is used, after the reaction is finished, the reaction mixture can be extracted with dichloromethane and then can be evaporated in a vacuum to obtain the crude cyanohydrins, which can be used directly for the preparation of compound 1 . The excess $\mathrm{NaCN}$ can be treated with sodium thiosulfate, and it is easier to safely control its use in the lab.

\section{Change benzene to dichloromethane to give 2,5-dithydrothioph-ene-3,4-dicarboxylic acid anhydride}

In refs. 11 and 17 , benzene was used to recrystallize 2,5-dithydrothiophene-3,4-dicarbo- xylic acid anhydride (compound 3). As is well known, benzene is toxic and not environmentally friendly. When dichloromethane is used to replaced benzene, similar results have been achieved for the product (compound 3). Thus, dichloromethane was deemed 
to be a more suitable solvent to treat this crude reaction.

\section{Factors influencing the synthesis of Cantharidin intermediates}

The high-performance liquid chromatography (HPLC) data in Table 1 show the results of the D-A reaction by comparing several types of ionic liquids at different reaction temperatures and reaction times ${ }^{18}$. It is evident that this reaction depends on both the reaction conditions and the types of ionic liquids. For example, in entry $\mathrm{A}$, the time to consume compound 3 was about $10 \mathrm{~h}$ at $45^{\circ} \mathrm{C}$; when the temperature was decreased to $25^{\circ} \mathrm{C}$, the time increased to $30 \mathrm{~h}$. This means that higher temperatures contribute more quickly to reaction rates and shorten the reaction times. But the yield of compound 4 also was reduced (from $90 \%$ down to $80 \%$ ), so the suitable reaction temperature and reaction time depend on the intent of the experiments.

Table 1 also shows that the D-A reaction proceeds to completion in ionic-liquids possessing of the imidazole ring at $35^{\circ} \mathrm{C}$ for $20 \mathrm{~h}$. This is a better result than a pyrrolidine ring or pyridine ring containing ionic liquids, in which case the reaction cannot be completed even at $45^{\circ} \mathrm{C}$ for $20 \mathrm{~h}$, to obtain Synthesis of Sulfur-containing dehydrocantharidin(SD). The factors that affect this maybe are the different ectric dipole moment which the order is imidazole ring $(1.58)>$ pyrrolidine ring $(0.29)>$ pyridine ring $(-0.79)^{19}$.These results confirm that the imidazole ring containing ionic liquids is the best choice for this D-A reaction.

As seen in Table 1, the length of the substituent chain on the imidazole ring can affect the D-A reaction. First, from butyl to hexyl, the longer the chain of the substituent in position 1 of the imidazole ring, the lower the yield of compound 4, and compound 3 cannot be fully consumed. This may explain why the yield of compound 4 in entry $\mathrm{A}$ is $86 \%$, which is much higher than the yield in entry $\mathrm{C}$, which is $57 \%$ under the same reaction conditions. Additionally, the yield of D is lower than the yield of $F$. As the chain length increases from hexyl to octyl, however, the yield also increases and approaches the yield of the butyl group, which is $88 \%$ for entry B. The reason maybe is the substituent effect. ${ }^{20,21}$

The type of salts in the ionic liquids also affected the D-A reaction. When entry D and entry $\mathrm{C}$ both have a hexyl-substituted imidazole ring, but entry $\mathrm{C}$ has borate salt and entry $\mathrm{D}$ has phosphorus acid salt, the difference in the conversion ratio is significant. In entry D, only $5 \%$ of compound 3 was not reacted, whereas $35 \%$ of compound 3 still was not reacted in entry $\mathrm{C}$. Phosphoric acid salt ionic liquid contributes a better conversion ratio than borates, and this trend was supported by the comparison between entry $\mathrm{F}$ and entry $\mathrm{A}$. By comparing entry A (borate salt) with entry $\mathrm{E}$ (sulfonyl imide salt), it is evident that the conversion ratios of compound 3 were almost the same. This mean that a variety of salts can affect the conversion ratio from compound 3 to compound 4 and demonstrates that phosphoric salt-type ionic liquid is better than types of borate salt and sulfonyl imide salt. The reason maybe is what the ability of absorb electrons were different ${ }^{22}$.

The ionic liquid with a single substituent in pyridine ring $(\mathrm{G})$ delivered the lowest yield. When the disubstituent pyridine ring was used, from $\mathrm{H}$ to $\mathrm{K}$, the yields were $22 \%$ for I, $35 \%$ for J, and $51 \%$ for $\mathrm{K}$. This means that means chlorine $(\mathrm{Cl})$ salt is better than bromine $(\mathrm{Br})$ salt and 3-methyl is better than 4-methyl. The yield of $\mathrm{H}$ was increased up to $62 \%$, and the yield of $\mathrm{L}$ was $51 \%$ when disubstituent pyrrolidine ring was used.

Table 1

The influence of different ionic liquids on the synthesis of SDs

\begin{tabular}{cccccc}
\hline \multirow{2}{*}{ Entry } & Ionic Liquid & Temp/ & Time/h & Compound 3 & Compound 4-exo \\
& & $\mathrm{C}$ & & & $90 \%$ \\
A & 1-butyl-3-methylimidazolium tetrafluoroborate & 25 & 30 & 0 & $86 \%$ \\
& & 35 & 20 & 0 & $80 \%$ \\
B & 1-octyl-3-methylimidazolium tetrafluoroborate & 35 & 20 & 0 & $88 \%$ \\
C & 1-hexyl-3-methylimidazolium tetrafluoroborate & 35 & 20 & $38 \%$ & $57 \%$ \\
D & 1-hexyl-3-methylimidazolium & 35 & 20 & $5 \%$ & $93 \%$ \\
E & hexafluorophosphate & 35 & 20 & 0 & $90 \%$ \\
\hline
\end{tabular}


Table 1 (continued)

\begin{tabular}{|c|c|c|c|c|c|}
\hline $\mathrm{F}$ & $\begin{array}{l}\text { 1-butyl-3-methylimidazolium } \\
\text { hexafluorophosphate }\end{array}$ & 35 & 20 & 0 & $96 \%$ \\
\hline $\mathrm{G}$ & 1-butylpyridinium tetrafluoroborate & 45 & 20 & $90 \%$ & $9 \%$ \\
\hline $\mathrm{H}$ & 1-ethyl-3-methylpyridinium ethyl sulfate & 45 & 20 & $37 \%$ & $62 \%$ \\
\hline I & 1-butyl-4-methylpyridinium bromide & 45 & 20 & $77 \%$ & $22 \%$ \\
\hline $\mathrm{J}$ & 1-butyl-4-methylpyridinium chloride & 45 & 20 & $52 \%$ & $35 \%$ \\
\hline $\mathrm{K}$ & 1-butyl-3-methylpyridinium chloride & 45 & 20 & $48 \%$ & $51 \%$ \\
\hline $\mathrm{L}$ & 1-ethyl-1-methylpyrrolidinium bromide & 45 & 20 & $48 \%$ & $51 \%$ \\
\hline
\end{tabular}

Table 2

The HPLC analysis data of different solvent extraction for ionic-liquid recycling

\begin{tabular}{|c|c|c|c|c|c|}
\hline $\begin{array}{c}\text { solvent } \\
\text { Percentage } \\
\end{array}$ & $\mathrm{Et}_{2} \mathrm{O}^{*}$ & $\mathrm{EtOH}^{* *}$ & $\mathrm{CHCl}_{3}$ & EtOAc & $\mathrm{CH}_{3} \mathrm{CN}$ \\
\hline Compound 4 in the residues & $29 \%$ & $24 \%$ & $69 \%$ & $49 \%$ & $67 \%$ \\
\hline Ionic liquid in the extraction & $30 \%$ & $65 \%$ & $36 \%$ & $11 \%$ & $83 \%$ \\
\hline
\end{tabular}

\section{Recycle the ionic liquids}

Ionic liquids are expensive and recycling these liquids is key to their use in scaled-up and commercial-scale preparations. Following are the experimental details of the ionic-liquid recycling. When 1-butyl-3-methylimidazolium tetrafluoroborate was used as the ionic liquid, the $\mathrm{D}-\mathrm{A}$ reaction mixture was divided into five portions and extracted with ether, ethanol, chloroform, ethyl acetate, and acetonitrile. Table 2 shows the HPLC analysis data for each extraction and the residues.

As shown in Table 2, we used HPLC to analyze the ratio of compound 4 in the residues and the recycle ratio of the ionic liquid in the extractions, after we treated the mixture with one of the five organic solvents and separated the extractions from the residues. The ionic liquid (1-butyl-3-methylimidazolium tetrafluoroborate) remaining in the residue was the highest for the extraction with diethyl ether $\left(\mathrm{Et}_{2} \mathrm{O}\right)$, lower for ethanol (EtOH), and the lowest for acetonitrile $\left(\mathrm{CH}_{3} \mathrm{CN}\right)$, because the ionic liquid could be dissolved easily in EtOH and $\mathrm{CH}_{3} \mathrm{CN} \cdot{ }^{17,23}$ Moreover, the solubility of compound 4 in $\mathrm{EtOH}$ or $\mathrm{CH}_{3} \mathrm{CN}$ was poor. After the mixture was extracted with $\mathrm{CH}_{3} \mathrm{CN}$ or EtOH, most of compound 4 could be collected in the residues by filtering the extraction. After removing the organic solvents from the extraction, we recycled the ionic liquid. Additionally, compound 4 decomposes in aqueous $\mathrm{EtOH}$, which further lowered the yield of compound 4 in the residue. Because compound 4 and the ionic liquid were well dissolved in ethyl acetate and chloroform, the isolation of the target compound 4 could not be achieved while recycling the ionic liquid. Therefore, we conclude that $\mathrm{CH}_{3} \mathrm{CN}$ is the best organic solvent to recycle the ionic liquid without tampering with the separation of compound 4.

\section{CONCLUSION}

The SD was efficiently synthesized starting form methanol and mercapto acetic acid which were basic chemical raw materials. The structures of (I) (II) and 0 4 were confirmed by ${ }^{1} \mathrm{H}$ NMR, ${ }^{13} \mathrm{C}$ NMR, HMBC, HMQC and HRMS. Effects of ionic liquid, reaction time and temperature on the D-A reaction were investigated as well. The optimum conditions conditions were as follows: 1-butyl-3-methylim- idazoliumtetrafluoroborate was as ionic liquid, reaction at $35^{\circ} \mathrm{C}$ for $20 \mathrm{~h}$. Because simplicity of operator and conveniently of the post-treatment on this process, which could be further developed at an industrial scale for the synthesis of CI and is destined to be an environmentally friendly way to solve the lack of cantharis as a natural resource.

\section{REFERENCES}

1. Y. B. Zeng, X. L. Liu, Y. Zhang, C. J. Li, D. M. Zheng, Y. Z. Peng, X. Zhoug, H. F. Du, C. B. Tan, Y. Y. Zhang and D. J. Yang, J. Natural Prod., 2016, 79, 2032.

2. H. F. Du, Y. B. Zeng, Y. Zhang and X. L. Liu, J. World Sci. Techn./Modern. Traditional Chinese Med. Mater. Medica, 2014, 16, 869.

3. J. Luo and G. S. Xi, China Pharmacy, 2007, 27, 2140.

4. H. W. Dong, C. M. Liu, Q. Q. He and L. H. Zhao, J.f Pharma. Practice, 2007, 5, 276. 
5. W. N. Zeng and Y. Lu, Chinese J. Org. Chem., 2006, 5, 579.

6. N. Chen, H. M. Li, G. P. Peng, Y. F. Zheng, C. Y. Li and Y. Jiang, J. Changchun Univ. Traditional Chinese Med., 2013, 1,25 .

7. F. C. Wei, J. Du, N. N. Wei, Y. Wang and S. W. Li, Progress Modern Biomedi., 2012, 8, 1586.

8. J. Gadamer, J. Arch. Pharm, 1914, 252, 609.

9. (a) G. Stork, E. E. van Tamelen, L. J. Friedman and A. W. Burgstahler, J. Am. Chem. Soc., 1951, 73, 4501; (b) G. Stork, E. E. van Tamelen, L. J. Friedman and A. W. Burgstahler, J. Am. Chem. Soc., 1953, 75, 384-392.

10. G. Schenck and R. Wirtz, Naturwissenshaften, 1953, 40, 531.

11. (a) W. G. Dauben and II. O. Krabbenhoft, J. Am. Chem. Soc., 1976, 98, 1992.; (b) W. G. Dauben, C. R. Kessel and K. H. Takemura, J. Am. Chem. Soc., 1980, 102, 6893.

12. P. A. Grieco, J. J. Nunes, and M. D. Gaul, J. Am. Chem. Soc., 1990, 112, 4595.
13. M. J. Earle, P. B. McCormac and K. R. Seddon, Green Chem., 1999, 1, 23.

14. I. Meracz and T. Oh, Tetrahedron Letters, 2003, 44, 6465.

15. W. G. Dauben, J. M. Gerdes and D. B. Smith, J. Org. Chem., 1985, 50, 2576.

16. B. R. Baker, M. V. Querry and A. F. Kadish, J. Org. Chem., 1948, 13, 123

17. X. Lu, H. Y. Zhou and J. S. Li, J. Chem. Eng. Equipment, 2008, 8, 29.

18. C. B. Tan, H. F. Du and X. L. Liu, Chinese J. Synth.c Chem., 2018, 26, 140.

19. Y. Wang and J. Z. Sun, Chem. J. Chinese Univ., 1993, 3, 372.

20. Q. Luo, Y. Zhu and D. You, Sci. China Press, 2016, 3, 342.

21. Z. Cao and X. Wu, Sci. China Chem., 2013, 7, 801.

22. H. Chen. Zhejiang Universities, 2015.

23. J. P. Fan, J. Cao, T. Kong and L. Zhang, J. Nanchang. Univ. (Eng. Techn.), 2009, 4, 334. 